\title{
Knowledge creation in pandemic time: Challenges and opportunities
}

\author{
Cheng-Jen “CJ”'Liu, The MITRE Corporation, cjliu@mitre.org ${ }^{1}$ \\ Wenli Wang, Robert Morris University,wangw@rmu.edu
}

\begin{abstract}
The Covid-19 pandemic has challenged the environment and process of knowledge creation. Most, if not all, knowledge-creating firms were forced to quickly adapt to new problem-solving practices.

Knowledge origination and transfer virtually via modern information and communication systems have supplemented or even replaced face-to-face interactions in physical proximity. The traditional SECI knowledge creation processes, e.g., Socialization, Externalization, Combination, and Internalization, were revised to accommodate more, if not all, virtual presences of knowledge creators and learners. For example, teleconferencing, cloud computing, and virtual machines enabling simultaneous audiomessage-visual communication, real-time remote screen and contents sharing, and video recording have been highly effective and well appreciated. Productivity boost at workplace may motivate continuation of virtual knowledge creation practices even post-pandemic when physical proximity is no longer an issue. Moreover, the importance of phronesis and leadership were discussed and demonstrated an example of lacking phronetic executive leadership at certain times during the pandemic.
\end{abstract}

Keywords: Knowledge Creation, SECI, Ba, Phronesis, Leadership, Pandemic

\section{Introduction}

The Covid-19 pandemic has been an ongoing global public health catastrophe caused by severe acute respiratory syndrome coronavirus 2 (SARS-CoV-2). Its outbreak first occurred in December 2019 in Wuhan, China (WHO, 2021, July 2). World Health Organization (WHO, 2020, March 11) proclaimed it as a pandemic on March 11, 2020. Subsequently, the United States, along with the rest of the world, also entered this disastrous chaos about mid-March, where many cities and even counties were forced to be locked down. Most offices, factories, businesses, schools, and public mass transportation had to be

\footnotetext{
${ }^{1}$ The first author's affiliation with The MITRE Corporation is provided for identification purposes only. It is not intended to convey or imply MITRE's concurrence with, or support for the positions, opinions, or viewpoints expressed by the authors. This work was an independent research effort.
}

The authors also declare that the research was conducted in the absence of any commercial or financial relationships that could be construed as a potential conflict of interest, and thank Drs. P. Kovacs and F. Y. Robinson, and all peer reviewers for their valuable comments and critiques.

Approved for Public Release, Distribution Unlimited. Public Release Case Number 21-1780.

(C) 2021 The MITRE Corporation. ALL RIGHTS RESERVED. 


\section{Issues in Information Systems}

Volume 22, Issue 1, pp. 306-319, 2021

closed, and people were directed to wear masks and practice social distancing to prevent virus spread through people's close encounters due to aerosol transmission (U.S. Department of Health \& Human Services, Centers for Disease Control and Prevention, 2020, September 4).

The suppression of people's near physical contact has brought up unprecedented challenges in knowledge creation. The physical portion of both the SECI process of knowledge creation, i.e., Socialization, Externalization, Combination, and Internalization (Nonaka \& Takeuchi, 1995) and the four affiliated characteristic ba for knowledge creation, i.e., originating, interacting, cyber, and exercising (Nonaka \& Konno, 1998) have been largely prohibited or reduced.

This research addresses challenges associated with lacking physical contacts and discusses the opportunities in primarily "virtual" knowledge creation during the Covid-19 pandemic through the following research questions:

RQ1. How was the SECI process of knowledge creation affected by the Covid-19 pandemic? RQ2. How should "ba" for knowledge creation adapt to the pandemic?

RQ3. What roles do phronesis and leadership play in knowledge creation in pandemic time?

Observations of two knowledge-creating organizations were made to qualitatively illustrate the answers to the above research questions, namely: (a) a systems engineering corporation representing a large knowledge creation enterprise, and (b) a private university representing academic teaching and research organization.

\section{Literature review}

\section{Knowledge and Knowledge Type}

Polanyi (1966) examined his idea of human knowledge from a harmonious view of thought and existence rooted in the emerging universe. He considered human knowledge by starting with "we can know more than we can tell." (p. 4). Davenport and Prusak (1998, p. 5) defined knowledge as "a fluid mix of framed experience, values, contextual information, and expert insight that provides a framework for evaluating and incorporating new experiences and information."

There are two main knowledge types: tacit vs. explicit (Nonaka \& Takeuchi, 1995). Tacit knowledge is subjective, experimental, contextual, personal, and intuitive "know-how" that is difficult to write down, visualize, or transfer. Explicit knowledge is objective, articulated, codified, formalized, and rational "know-what" which can be expressed in a context-free manner and recorded in documents, memos, manuals, databases, etc. Cawthorne (2015) also defined embedded knowledge as skills and understanding locked in processes, products, rules, or organizational cultures, such as informal routines, codes of conduct, and organizational ethics.

\section{Knowledge Creation}

The following four perspectives of knowledge creation were discussed in details below: SECI process and its dimensions, ba, phronesis, and leadership. 


\section{SECI Process}

Nonaka and Takeuchi (1995) first focused on the epistemological dimension of the SECI process model of knowledge creation (Nonaka \& Takeuchi, 2020, Figure 3.2), as shown below in Figure 1.

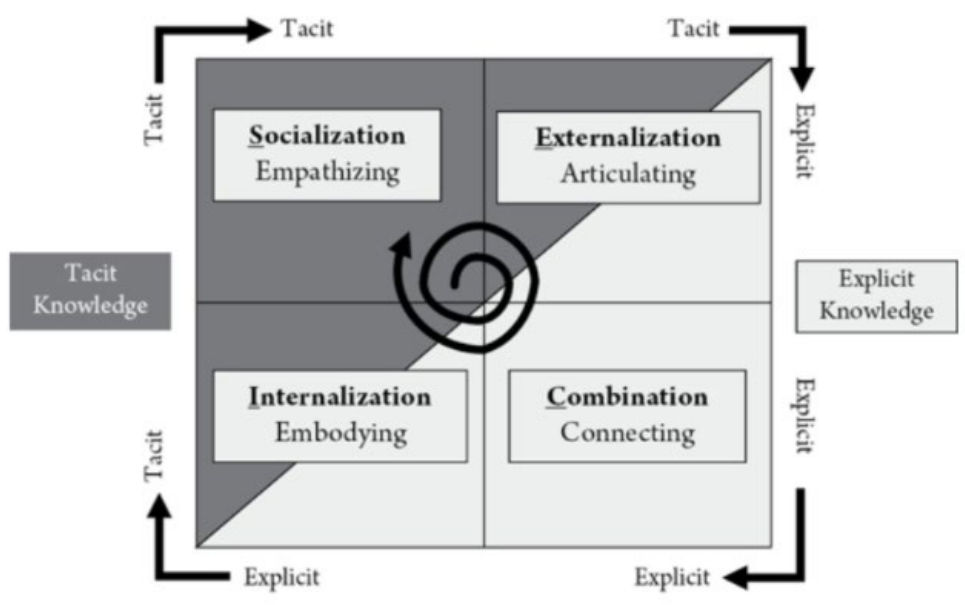

Figure 3.2. The epistemological dimension.

Figure 1: The SECI Process Model of Knowledge Creation - The Epistemological Dimension (Nonaka \& Takeuchi, 2020, Figure 3.2)

The SECI process model contains:

1. Socialization -- implies sharing tacit knowledge between or among individuals. That is, people spend time together so that knowledge can be acquired through physical proximity.

2. Externalization -- involves the expression of tacit knowledge and its translation into comprehensible forms that can be understood by others. An individual commits to a team and becomes one of them. The expression of tacit knowledge is in fact its conversion into explicit knowledge; to be able to do this, figurative language and visuals are essential.

3. Combination -- is the conversion of explicit knowledge into more complex sets of explicit knowledge. Key issues are communication, diffusion, and the systemization of knowledge. New knowledge is spread among a larger context, and this knowledge is edited to make it more usable.

4. Internalization -- is the conversion of newly created explicit knowledge into tacit knowledge. The individual has to identify the knowledge relevant to oneself.

Nonaka and Takeuchi also depicted the ontological dimension of knowledge creation (2020, Figure 3.3), as shown below in Figure 2. 


\section{Issues in Information Systems}

Volume 22, Issue 1, pp. 306-319, 2021

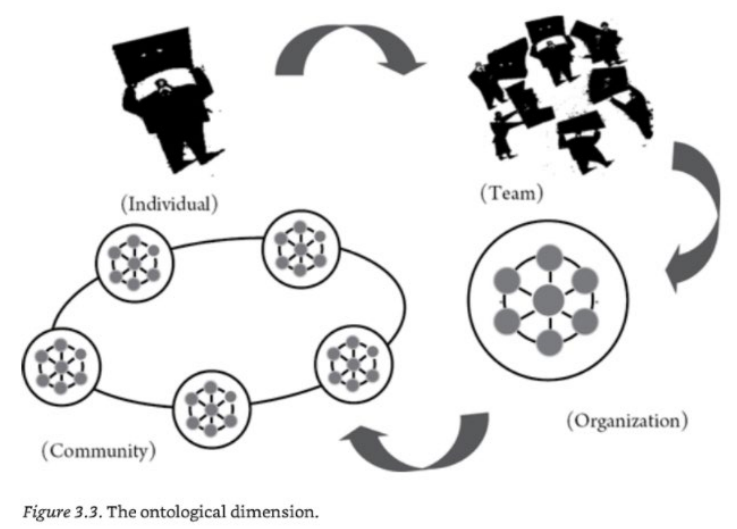

Figure 2: Knowledge Creation - The Ontological Dimension (Nonaka \& Takeuchi, 2020, Figure 3.3)

Then Nonaka and Takeuchi integrated the epistemological dimension with the ontological dimension together and created an updated SECI process model of knowledge creation (Nonaka \& Takeuchi, 2020, Figure 3.4), as shown in Figure 3.

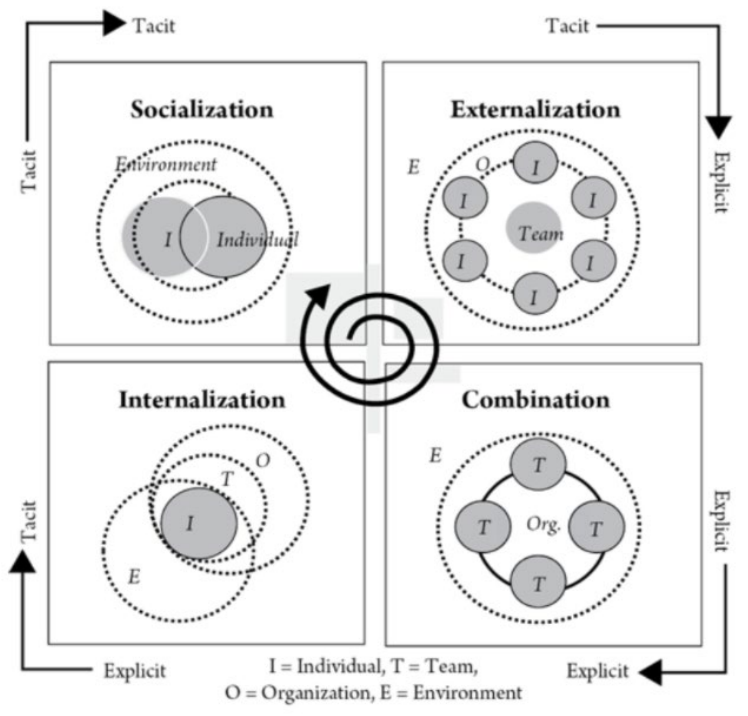

Figure 3.4. The updated SECI Model.

Figure 3: The Updated SECI Process Model of Knowledge Creation (Nonaka \& Takeuchi, 2020, Figure 3.4)

\section{$B a$}

Nonaka and Konno (1998, p. 44) introduced the concept of "ba" for provisioning a foundational context or environment for and facilitating knowledge creation. The word ba is a Japanese term that roughly translates into the English word "place", but not a space (Konno, 2013, p. 211). More specifically, ba (Hiragana ば, Katakana バ, Kanji 場) is defined as (a) place, spot, space; (b) occasion, situation; and (c) field as in Gestalt psychology (Haibuihoang, 2015, November). In Chinese, ba (Kanji) 場 has the same semantic meanings (Collins, 2021). 


\section{Issues in Information Systems}

Volume 22, Issue 1, pp. 306-319, 2021

The ba concept was originally proposed by Nishida (1970, 1990), further developed by Shimizu (1995), and adapted by Nonaka and Konno (1998) for elaborating the SECI process Model of knowledge creation. Nonaka and Konno (1998) believed their knowledge creation concept differentiates ba from ordinary human interaction because knowledge is embedded in ba as a shared space, where it is then acquired through one's own experience or reflections on the experiences of others. Ba is the shared space serving as a foundation for knowledge creation, and knowledge is embedded in ba. If knowledge becomes separated from ba, it becomes information. Information can exist in media or networks, but knowledge cannot because it is intangible (p. 41).

Knowledge is dynamic and without boundary, however, if not used at a specific place, knowledge is of no value. Using knowledge requires concentrating knowledge resources in a certain context. Ba is the place for facilitating resource concentration of knowledge assets and intellectualizing capabilities within the knowledge creation process. Ba collects applied knowledge and integrates it. An example of ba is a project team, a place where people of different capabilities are brought together to create knowledge (p. 41). Nonaka showed some great examples of ba's specifically designed to enable knowledge creation and sharing in companies such as NTT DoCoMo and Toyota (Elearningpost, 2001).

The four characteristics of ba that correspond to the four SECI processes (Nonaka \& Konno, 1998, p. 45, Figure 3) are depicted below in Figure 4.

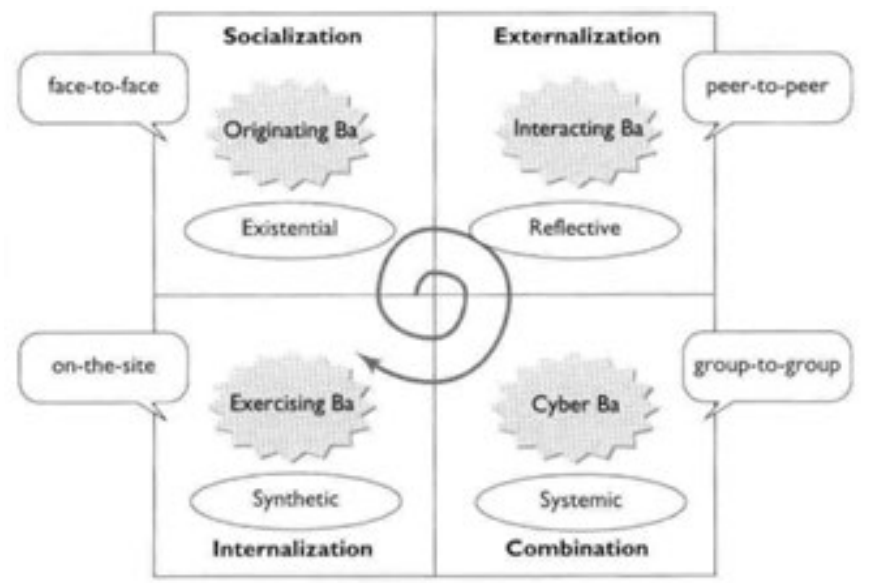

Figure 4: The Four Characteristics of Ba. (Nonaka \& Konno, 1998, Figure 3)

These four characteristics of ba are:

1. Originating ba -- is the world where individuals share feelings, emotions, experiences, and mental models, and also the primary ba where the knowledge creation begins and enables socialization among individuals. Face-to-face experiences are the key to conversion and transfer of tacit knowledge.

2. Interacting ba -- is more consciously constructed, as compared to originating ba. Selecting people with the right mix of specific knowledge and capabilities for a project team, taskforce, or crossfunctional team is critical. Through dialogue, individual's mental models and skills are converted into common terms and concepts. Two processes operate in concert: individuals share the mental model with others, but also reflect and analyze their own.

3. Cyber ba -- is a place of interaction in a virtual world instead of physical. And it corresponds to the combination process. Here, the combining of new explicit knowledge with existing 


\section{Issues in Information Systems}

Volume 22, Issue 1, pp. 306-319, 2021

information and knowledge generates and systematizes explicit knowledge throughout an organization.

4. Exercising ba -- supports the internalization phase and facilitates the conversion of explicit knowledge to tacit knowledge. Focused training with senior mentors and colleagues consists primarily of continued exercises that stress certain patterns and working out of such pattern. Rather than teaching based on analysis, learning by continuous self-refinement through on-job or peripheral training. Active participation is stressed.

Each of the four characteristics of ba specifically describes an instance associated with each of the four knowledge transformation processes. These ba characteristics offer platforms for specific stages in the knowledge creation process. Each of them supports a particular transformation process to speed up the conversion in knowledge creation.

Six additional forms of ba have further been introduced and discussed. Each can be thought of as a shared space for emerging relationships (Nonaka \& Konno, 1998; Nonaka \& Takeuchi, 2020):

1. External ba (2020, p. 148): various subtypes created by and connected with stakeholders with shared values at different levels from individual to organization to community.

2. Internal ba (2020, p. 149): the headquarters of an enterprise as an ideal internal ba for information sharing and solution development.

3. Physical ba (1998, p. 40): office, dispersed business space.

4. Virtual or online ba $(1998$, p. $40 ; 2020$, p. 154): chat room, text messaging, social media platforms, emailing, voice/video telephony, tele-conferencing.

5. Mental or cognitive ba (1998, p. 40; 2020, p. 149): shared experiences, believes, ideas, or ideals.

6. Any combination of the above.

The newly introduced forms of ba address the location and fundamental conditions of knowledge creation in a context which harbors meaning, according to existentialism theory (Nonaka \& Takeuchi, 2020). Similarly, Buunk, Smith, and Hall (2019) further studied tacit knowledge sharing in online environments on how ba is located within a technical platform.

\section{Phronesis and Leadership}

Nonaka, Toyama, and Hirata (2008) introduced new ideas of phronesis - for leading the knowledgecreating firm, and leadership - for fostering distributed excellence, and shared their vision and values for the common good at driving objectives. Phronesis is the ability to make a decision that is suitable for the context, where one has to be able to quickly recognize a situation and understand what is required to act properly in that context (p. 57). Simply put, phronesis can be regarded as practical wisdom (Kase, González-Cantón, \& Nonaka, 2014, p. 1).

The concept of phronesis originates with Aristotle (Kraut, 2018). In the Nicomachean Ethics (c. 350 BC), he classified three types of knowledge: (a) Episteme, (b) Techne, and (c) Phronesis. Phronesis is a moral and intellectual virtue rooted in a natural and human capacity "to do the right thing in the right place, at the right time in the right way" (Carr, 2005, p. 133; MacIntyre, 2007, p. 141). More an intellectual virtue than a moral virtue, phronesis is often learned through instruction and not practice, but it is very closely connected to the moral virtues. Without phronesis, it would be impossible to practice the moral virtues properly. A person who has all the right moral virtues knows what ends to pursue, but without phronesis, that person will not know how to set about pursuing the right ends (Helgesen, 2008). 
In the SECI spiral model of knowledge creation, Nonaka and Takeuchi showed that practical wisdom grows in an upward spiral of iterative SECI knowledge creation processes (2020, Figure 3.1) as shown in Figure 5.

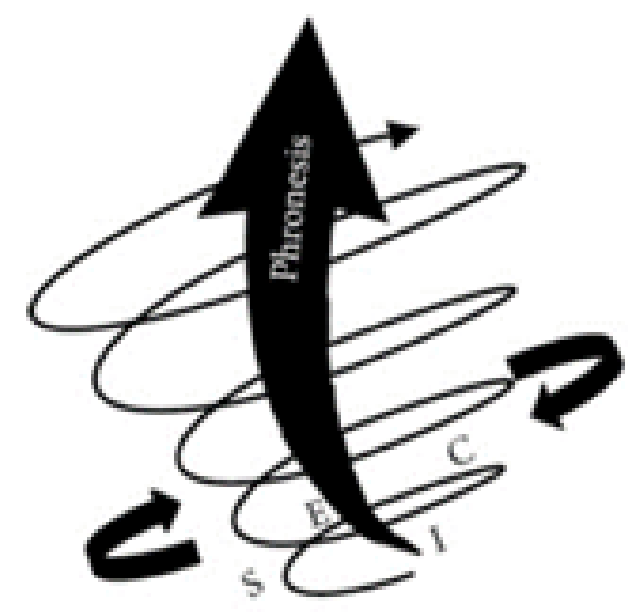

Figure 5: The SECI Spiral Model of Knowledge Creation (Nonaka \& Takeuchi, 2020, Figure 3.1)

Nonaka, et al. (2008) explored issues of phronetic leadership, which is described as flexible, distributed, and determined by the context. Knowledge leaders must be able to connect various ba both inside and outside the organization to form a self-organizing ecosystem of knowledge (p. 58).

In practice, the organizational knowledge creation theory, consisting of the SECI process, ba, phronesis, and leadership, has been extensively applied. Nishihara, Matsunaga, Nonaka, and Yokomichi (2018a, $2018 \mathrm{~b}$ ) published the operational results out of nine distinct perspectives and a dozen of varying case studies, based on the successes of numerous applications extended to community development and public administrations, respectively. Sizable amounts of evidence have been accumulated to support the theory and contribute to the existing body of knowledge.

Nonaka and Takeuchi (2020) further revisited the extension of practical wisdom, as companies around the globe sustain endlessly knowledge creation with the intention to convert it to wise actions over time. The authors asserted that while knowledge-creating firms focusing on tacit/explicit knowledge can foster innovations, knowledge creation cannot be maintained without having wisdom about human interactions as well as how that would influence organizational structures and practices.

However, all those published case studies introduced above were conducted before the Covid-19 pandemic. What would be the impact of the Covid-19 pandemic on this theory? How can the theory be further elevated to a new level of maturation by addressing the challenges and opportunities due to the pandemic? These two questions establish the motivation of this research.

\section{Methodology}

The preceding literature review has provided an extensive coverage on the organizational knowledge creation theory which was developed and updated by Nonaka and Takeuchi $(1995,2020)$, summarized by Cook and Brown (1999), and supplemented by relevant literature in the past 25 years (Davenport \& 


\section{Issues in Information Systems}

Volume 22, Issue 1, pp. 306-319, 2021

Prusak, 1998; Nonaka \& Konno, 1998; Carr, 2005; Konno, 2013; Cawthorne, 2015; Nishihara, et al., 2018a, 2018b; Buunk, Smith, \& Hall, 2019).

This research applies qualitative observations and discussions to utilize and extend the insights obtained from the literature review. In the discussions, the four main components of the knowledge creation theory -- SECI process, ba, phronesis, and leadership were examined and extended.

An exemplar workplace and a model school were chosen to study how knowledge creation practices were impacted by the Covid-19 pandemic. Observations on these two knowledge-creating organizations were made to qualitatively illustrate the answers to the research questions. These two organizations are: (a) a systems engineering corporation representing a large knowledge creation enterprise, and (b) a private university representing an academic teaching and research organization.

\section{Results}

\section{RQ1. How was the SECI process of knowledge creation affected by the Covid-19 pandemic?}

During the Covid-19 pandemic, the organizational knowledge creation process has met many challenges in that people were required to wear masks, practice social distancing, avoid crowd gathering, and stay home for nonessential workers to keep away from the workplace and school. Wearing masks and practicing social distancing made it difficult for in-person dialoguing and side-by-side collaboration, if achievable. Working or studying from home, if remote virtual task or online education engagement were feasible, had become the only solution and privilege for some people. All those aforementioned contingencies collectively prohibited, impeded, or discouraged close interaction and communication between or among individuals for socialization, such as in-person networking/dialoguing, travel-and-meet for team collaboration, hands-on training, or on-the-job learning, when physical gathering deemed necessary.

Faced by the challenges of stay home orders and no in-person interaction, it was difficult to proceed with organizational knowledge creation at an empty workplace representing unavailable physical ba. The opportunities brought about by the pandemic to the legacy organizational knowledge creation practice were facilitated by the elevated levels of virtual or online ba. Socialization does not have to be face-toface in physical proximity. Externalization needs not to be peer-to-peer articulation and reflection during in-person team meetings. Combination continues occurring in cyber ba, however, individuals doing the tasks no longer need to gather in physical ba to collaborate and coordinate. Internalization does not have to rely on in-person training.

In other words, the physical presence of human actors as members of a team and organization is no longer essential in all of the four SECI processes. Throughout the pandemic, remote work has increased the productivity of some workers and businesses, even at a level of productivity boost (Strain, 2021, May 21).

For example, the workplace of a large U.S. systems engineering corporation was an example of physical ba prior to the pandemic. More importantly, it has quickly taken advantage of and made the best use of information and communication systems technologies to empower employees with teleworking and virtual audio-visual collaboration capabilities since the very start of the pandemic. There was no requirement for the employees to work onsite risking coronavirus infection.

For sustaining task execution, each and every employee was directed to bring home information and communication equipment, such as a computer, monitor, desktop phone, accessories, and even office 


\section{Issues in Information Systems}

Volume 22, Issue 1, pp. 306-319, 2021

chair. Moreover, an unprecedented provision of a smartphone was made available to every staff. It was directly shipped to each employee's home and came with an inclusive 5G-able service plan and paid software apps to facilitate communication, not only for voice and video, but also capable of sharing screen, text message, and file. All desktop-based office productivity software applications were also made available on one's mobile device as corresponding apps.

\section{RQ2: How should "ba" for knowledge creation adapt to the pandemic?}

The traditional context-centric tacit knowledge transfer processes have been largely enhanced by leveraging screen sharing and video recording to facilitate the procedure-based "know-how" show-and-tell. It is interesting to realize that the productivity of this workforce has highly elevated because of the elimination of physical commuting burden as well as the much easier and clearer on-screen presentation. Conversely, the transfer of codified and formalized explicit knowledge integrated the improved tacit knowledge transfer as an interacting counterpart. The mutual reinforcement effect resulting from promoted virtual and online ba has been observed and experienced.

For example, in an on-the-job training series offered by the systems engineering corporation on big data analytics, employees learned online from subject matter expert colleagues. On-premises and cloud-based virtual machines were utilized to facilitate online exercises while the instructors could selectively monitor trainees' computer screens remotely. Before the pandemic, all trainees met physically at a lab that the trainer needs to walk around to different lab computers to see trainees' progress to provide in-person assistance. This is exactly how virtual and online ba excels over the physical ba legacy with better effectiveness.

Similarly, on a cohort-based information systems and communications doctoral degree program of a major private university, prior to the pandemic, students had to travel to school for in-person learning and congregation-oriented networking for mutual support and communication. They had to stay at a local hotel for days to sustain either a whole week or three days in a weekend of in-person study at the school - a physical ba. Soon after the start of and during the pandemic, cohort learning has been converted to total online in virtual ba.

\section{RQ3. What roles do phronesis and leadership play in knowledge creation during the pandemic?}

Examining the Covid-19 pandemic situation in the United States during the first year in March 2020, there were definitely concerned leadership issues. The death tolls, overwhelmingly breaching numbers of hospitalization rates, and new cases have all reflected serious problems with the nation's top leadership (Murray \& Meyer, 2020, July 13). Phronesis was continuously missing, as scientific evidence-based factual statistics - examples of explicit knowledge were not integrated with healthcare experts' beliefs examples of tacit knowledge and adopted by the executive leaders for generating practical wisdom.

People in the United States had no choice and suffered during the first ten months of the pandemic from lacking phronetic leadership (Kristof, 2020, October 22) of the most powerful nation in the world, which can be regarded as a large knowledge-creating firm. It is clear that phronetic leadership is meant to perform and provide for the common goods with moral objectives - saving lives, keeping people safe, and mitigating healthcare and economic downturns. The new executive leadership team has started demonstrating more phronetic leadership such as donating a billion doses of vaccines to developing nations to curb the global suffering caused by the Covid-19 pandemic (Steinhauser \& Shah, 2021, June 10). 


\section{Issues in Information Systems}

Volume 22, Issue 1, pp. 306-319, 2021

\section{Discussion}

This research focused on the study of the organizational knowledge creation theory Nonaka and Takeuchi pioneered (1998) and the prominent practice of its four key components impacted by the Covid-19 pandemic. General organizational knowledge management was not investigated because it was not the focus of this paper.

Nonaka, Toyama, and Hirata (2008) reiterated ba (Chapter 5) in the Managing Flow, when they introduced the new process theory of the Knowledge-Based Firm. Importantly, in the foreword, Teece (2008, pp. ix-xvii) summarized the contributions Nonaka et al. had made to the field of strategic management - from the management of R\&D to knowledge management. Teece (pp. xii-xiii) also duly attested to the assertion of the significant role middle managers play in the middle-up-down management theory Nonaka and Takeuchi introduced (1995, Chapter 5). That is, in such a framework, it is the middle managers in the organization who "bring together the visionary ideas of top management and the chaotic realities of front-line workers" (p. xii) for creating knowledge. In other words, it is believed that "knowledge is created by middle managers. They are essential players in the SECI process" (p. xiii).

Organizational knowledge management is another important component of Nonaka and Takeuchi's organizational knowledge creation theory, particularly advocating the middle-up-down management process for knowledge creation (1995, Chapter 5). Extensive research and development efforts have since continued (Teece, 2013; Spender, 2013; Xu, 2013; Holden, 2013). Konno (2013) further introduced the management theory of ba, when he revisited the knowledge creating firm in the 'post-capitalist society' context. In its own right, extended research on organizational knowledge management deserves to be performed separately in the future work, thus not covered.

\section{Conclusion}

The Covid-19 pandemic has impacted knowledge creation practices. Due to the pandemic incurred contingencies, e.g., stay home order, prohibited crowd gathering, social distancing, and wearing masks, knowledge creators and learners could not meet in-person for face-to-face, peer-to-peer, team-to-team, and on-site-at-workplace in physical ba that requires close encounters. Virtual ba has become the main, if not the only, solution for replacing the physical counterpart to sustain the knowledge creation process. Knowledge can be created in the virtual world, presented externally on computer screens, and transferred via teleconferencing among tacit knowledge holders.

Phronetic leadership is in high demand - needed not only to address the above challenges in knowledge creation and lead the team to seek new opportunities but also to apply morality and practical wisdom to keep everyone safe from virus exposure at the workplace. Productivity gained from safe and economical remote work and online learning (Strain, 2021, May 21) encourages long-term adaptation of virtual knowledge creation even post-pandemic. The derivative benefits are abundant to all adopting corporations on lowered office resource need at the workplace, employee on decreased commuting time and transportation expense, city on diminished road traffic, and global community on carbon footprint reduction for supporting climate change mitigation (Reynolds, 2021). 


\section{Issues in Information Systems}

Volume 22, Issue 1, pp. 306-319, 2021

\section{References}

Aristotle. (c. 350 BC). Nicomachean Ethics (W. D. Ross, Trans.). Book VI(5). Retrieved from http://classics.mit.edu/Aristotle/nicomachaen.html

Buunk, I., Smith, C. F., \& Hall, H. (2019). Tacit knowledge sharing in online environments: Locating 'Ba' within a platform for public sector professionals. Journal of Librarianship and Information Science, 51(4), 1134-1145. doi:10.1177/0961000618769982

Carr, W. (Ed.). (2005). What is the philosophy of education? The Routledge Falmer Reader in the Philosophy of Education. Oxon: Routledge, 34-49.

Cawthorne, J. (2015). Social collaboration mediated knowledge management. CMS WiRE [Web blog post]. Retrieved from https://www.cmswire.com/social-business/social-collaboration-mediatedknowledge-management/

Collins. (2021). In Collins Mandarin Chinese English dictionary. Retrieved from https://www.collinsdictionary.com/dictionary/chinese-english/\%E5\%9C\%BA

Cook, S. D. N., \& Brown, J. S. (1999). Bridging epistemologies: The generative dance between organizational knowledge and organizational knowing. Organization Science, 10(4), 381-400. Retrieved from https://www.researchgate.net/publication/220041621 Bridging_Epistemologies The Generative Dance Between_Organizational_Knowledge and_Organizational_Knowing

Davenport, T. H., \& Prusak, L. (1998). Working knowledge: How organizations manage what they know (Reissued 2000). Cambridge, MA: Harvard Business School Press.

Elearningpost. (2001). Report from "Ba" - KM Asia 2001 [Web blog post]. Retrieved from http://www.elearningpost.com/articles/archives/report_from_ba km_asia_2001/

Haibuihoang. (2015, November). Meaning of ba in Japanese [Japanese dictionary]. Retrieved from http://www.romajidesu.com/dictionary/meaning-of-ba.html

Helgesen, S. (2008). The practical wisdom of Ikujiro Nonaka. Strategy Business Magazine, Organizations \& People (strategy + business). Retrieved from https://www.strategybusiness.com/media/file/sb53 08407.pdf

Holden, N. J. (2013). Russia's first handbook of knowledge management as a reflector of a KM landscape Sui Generis. In G. von Krogh, H. Takeuchi, K. Kase, \& C. González-Cantón (Eds.). Towards organizational knowledge: The pioneering work of Ikujiro Nonaka (Chapter 8). New York: Palgrave MacMillan.

Kase, K., González-Cantón, C, \& Nonaka, I. (2014). Phronesis and quiddity in management: A school of knowledge approach. Cham, Switzerland: Palgrave Macmillan. 


\section{Issues in Information Systems}

Volume 22, Issue 1, pp. 306-319, 2021

Konno, N. (2013). Revisiting the 'Knowledge Creating Firm' in the 'Post-Capitalist Society' context. In G. von Krogh, H. Takeuchi, K. Kase, \& C. González-Cantón (Eds.). Towards organizational knowledge: The pioneering work of Ikujiro Nonaka (Chapter 11). New York: Palgrave MacMillan.

Kraut, R. (2018) Aristotle's Ethics: 4. Virtues and deficiencies, continence and incontinence. In E. N. Zalta (Ed.) Stanford Encyclopedia of Philosophy (Summer 2018 Ed.). Retrieved from https://plato.stanford.edu/archives/sum2018/entries/aristotle-ethics/

Kristof, N. (2020, October 22). America and the virus: 'A colossal failure of leadership'. The New York Times, Opinion. Retrieved from https://www.nytimes.com/2020/10/22/opinion/sunday/coronavirus-united-states.html

MacIntyre, A. C. (2007). After virtue: A study in moral theory (3rd ed.). Retrieved from https://www3.nd.edu/ undpress/excerpts/P01162-ex.pdf

Murray, A. \& Meyer, D. (2020, July 13). On the COVID-19 front, the U.S. has had a massive leadership failure. Fortune, CEO Daily. Retrieved from https:/fortune.com/2020/07/13/us-health-careleadership-failure-covid-19-ceo-daily/

Nishida, K. (1970). Fundamental problems of philosophy: The world of action and the dialectical world. (D. A. Dilworth, Trans.). Tokyo: Sophia University.

Nishida, K. (1990). An inquiry into the good (M. Abe \& C. Ives, Trans.). New Haven, CT: Yale University Press.

Nishihara, A. H., Matsunaga, M., Nonaka, I., \& Yokomichi, K. (2018). Knowledge creation in community development: Institutional change in Southeast Asia and Japan. Cham, Switzerland: Palgrave Macmillan.

Nishihara, A. H., Matsunaga, M., Nonaka, I., \& Yokomichi, K. (2018). Knowledge creation in public administrations: Innovative government in Southeast Asia and Japan. Cham, Switzerland: Palgrave Macmillan.

Nonaka, I., \& Konno, N. (1998). The concept of "Ba": Building a foundation for knowledge creation. California Management Review, 40(3), 40-54. Retrieved from https://home.business.utah.edu/actme/7410/Nonaka\%201998.pdf

Nonaka, I., \& Takeuchi, H. (1995). The knowledge-creating company: How Japanese companies create the dynamics of innovation. New York: Oxford University Press.

Nonaka, I., \& Takeuchi, H. (2020). The wise company: How companies create continuous innovation. New York: Palgrave MacMillan.

Nonaka, I., Toyama, R., \& Hirata, T. (2008). Managing flow: A process theory of the knowledge-based firm. New York: Palgrave MacMillan.

Polanyi, M. (1966). The Tacit Dimension. Chicago: The University of Chicago Press (Republished 2009). 


\section{Issues in Information Systems}

Volume 22, Issue 1, pp. 306-319, 2021

Prusak, L. \& Davenport, T. H. (2013). Knowledge after the knowledge creating company: A practitioner perspective. In G. von Krogh, H. Takeuchi, K. Kase, \& C. González-Cantón (Eds.). Towards organizational knowledge: The pioneering work of Ikujiro Nonaka (pp. 255-262). New York: Palgrave MacMillan.

Reynolds, B. W. (2021). The environmental impacts of remote work: Stats and benefits. Flexjobs [Web blog post]. Retrieved from https://www.flexjobs.com/blog/post/telecommuting-sustainabilityhow-telecommuting-is-a-green-job/

Shimizu, H. (1995). Ba-principle: New logic for the real-time emergence of information. Holonics, 5(1), $67-79$.

Spender, J.-C. (2013). Nonaka and KM's past, present and future. In G. von Krogh, H. Takeuchi, K. Kase, \& C. González-Cantón (Eds.). Towards organizational knowledge: The pioneering work of Ikujiro Nonaka (Chapter 2). New York: Palgrave MacMillan.

Steinhauser, G. \& Shah, S. (2021, June 10). U.S. Covid-19 vaccine donation to boost developing world's pandemic fight. The Wall Street Journal. Retrieved from https://www.wsj.com/articles/u-s-covid19-vaccine-donation-to-boost-developing-worlds-pandemic-fight-11623336131

Strain, M. R. (2021, May 21). Covid boosted productivity. Post-covid will boost it more. Bloomberg Opinion, Economics. Retrieved from https://www.bloomberg.com/opinion/articles/2021-0521/after-covid-pandemic-productivity-gains-will-keep-expanding

Teece, D. (2008). Foreword: From the management or R\&D to knowledge management. Some contributions of Ikujiro Nonaka to the field of strategic management. In I. Nonaka, R. Toyama, \& T. Hirata, (pp. ix-xvii). Managing flow: A process theory of the knowledge-based firm. New York: Palgrave MacMillan.

Teece, D. (2013). Nonaka's contribution to the understanding of knowledge creation, codification and capture. In G. von Krogh, H. Takeuchi, K. Kase, \& C. González-Cantón (Eds.). Towards organizational knowledge: The pioneering work of Ikujiro Nonaka (Chapter 1). New York: Palgrave MacMillan.

U.S. Department of Health \& Human Services, Centers for Disease Control and Prevention. (2020, September 4). Timing of state and territorial COVID-19 stay-at-home orders and changes in population movement - United States, March 1-May 31, 2020. Morbidity and Mortality Weekly Report (MMWR) 69(35),1198-1203. Retrieved from https://www.cdc.gov/mmwr/volumes/69/wr/mm6935a2.htm

World Health Organization. (2020, March 11). WHO Director-General's opening remarks at the media briefing on COVID-19 - 11 March 2020 [Web blog post]. Retrieved from https://www.who.int/director-general/speeches/detail/who-director-general-s-opening-remarks-atthe-media-briefing-on-covid-19---11-march-2020

World Health Organization. (2021, July 2). Event 0, Dec 31, 2019. Timeline: WHO's COVID-19 response [Web blog post]. Retrieved from https://www.who.int/emergencies/diseases/novelcoronavirus-2019/interactive-timeline\#event-0 


\section{Issues in Information Systems}

Volume 22, Issue 1, pp. 306-319, 2021

$\mathrm{Xu}, \mathrm{F}$. (2013). The formation and development of Ikujiro Nonaka's knowledge creation theory. In G. von Krogh, H. Takeuchi, K. Kase, \& C. González-Cantón (Eds.). Towards organizational knowledge: The pioneering work of Ikujiro Nonaka (Chapter 3). New York: Palgrave MacMillan. 